\title{
ACADEMIC ANAESTHETIST
}

We are looking for a specialist anaesthetist interested in joining an enthusiastic, academically oriented Department of Anaesthesia.

The Sir Mortimer B. Davis-Jewish General Hospital is a 628 bed hospital located in Montreal and affiliated with McGill University. The Department of Anaesthesia is responsible for approximately 14,000 operating room cases and 4000 obstetrical deliveries per year.

Applicants should be certified by the Royal College of Physicians and Surgeons, and should be eligible for licensure in Quebec. Preference will be given to candidates interested in participating in the teaching and research activities of the Department.

In accordance with Canadian Immigration requirements, this advertisement is directed to Canadian citizens and permanent residents of Canada.

Submit applications with complete curriculum vitae to:

S. KJeiman, M.D., FRCPC, Anaesthetist-in-Chief

Sir Mortimer B. Davis-Jewish General Hospital

3755 Cote Ste. Catherine Road, Montreal, Quebec H3T 1 E2

\section{FELLOWSHIP IN LIVER TRANSPLANTATION ANESTHESIA}

The Department of Anesthesiology and Critical Care Medicine of the University of Pittsburgh School of Medicine is offering a 6- or 12-month fellowship in anesthesia for liver transplantation, including pediatric transplantation. The position is open to anesthesiologists who have completed approved training programs and to anesthesiology residents at the CA-3 level. A1 the University of Pittsburgh Medical Center about 500 adult liver transplants and 75 pediatric transplants are performed per year. The fellowship is supervised by specialists in liver transplantation. The program can be tailored to the individual goals of the applican and provides experience with state-of-the-art management and monitoring techniques. The fellow may also participate in anesthesia for donor organ procurement, postoperative care in the intensive care unit, and research.

To receive an applicarion form, send a curriculum virae 10:

Yoogoo Kang, M.D., Associate Professor

Department of Anesthesiology/CCM

University of Pittsburgh School of Medicine

1385 Scaife Hall, Pittsburgh, PA 1526

(412) 647-6466

\section{ANAESTHETIST: N.B.}

Required for the Dr. Georges-L. Dumont Hospital, Moncton. Candidate will join 5 other anaesthetists on fee-for-service basis. A 338 bed, tertiary care hospital in a city of 90,000 people.

Candidate must have a working knowledge of French or be ready to learn within a year. Apply to:

Medical Director

Dr. Georges-L. Dumont Hospital

330 Archibald Street

Moncton, New Brunswick

EIC $2 Z 3$

Telephone: (506) 858-3231

ANESTHESISTE: N. - B.

L'Hôpital Dr Georges-L. Dumont, Moncton; 338 lits, TACO, Médecine nucléaire et services tertiaires. Recherche anesthésiste pour se joindre à une équipe de cinq.

Doit parler français ou disposer à l'apprendre en dedans d'un an. Faire parvenir votre curriculum vitae:

\author{
Directeur médical \\ Hôpital Dr Georges-L. Dumont \\ 330, rue Archibald \\ Moncton, N.-B. \\ E1C 273
}

Téléphone: (506) 858-3231 